\title{
TU/e EmonOWEN

\section{A high-speed valve for surge control in a centrifugal compression system}

\section{Citation for published version (APA):}

Helvoirt, van, J., Jager, de, A. G., Steinbuch, M., \& Rosielle, P. C. J. N. (2007). A high-speed valve for surge control in a centrifugal compression system. In Proceedings of the 2007 IEEE International Conference on Control Applications (CCA 2007) part of the 2007 IEEE Multi-Conference on Systems and Control (MSC 2007) 1-3 October 2007, Singapore, Singapore (pp. 682-687). Institute of Electrical and Electronics Engineers. https://doi.org/10.1109/CCA.2007.4389311

DOI:

10.1109/CCA.2007.4389311

Document status and date:

Published: 01/01/2007

\section{Document Version:}

Publisher's PDF, also known as Version of Record (includes final page, issue and volume numbers)

\section{Please check the document version of this publication:}

- A submitted manuscript is the version of the article upon submission and before peer-review. There can be important differences between the submitted version and the official published version of record. People interested in the research are advised to contact the author for the final version of the publication, or visit the $\mathrm{DOI}$ to the publisher's website.

- The final author version and the galley proof are versions of the publication after peer review.

- The final published version features the final layout of the paper including the volume, issue and page numbers.

Link to publication

\section{General rights}

Copyright and moral rights for the publications made accessible in the public portal are retained by the authors and/or other copyright owners and it is a condition of accessing publications that users recognise and abide by the legal requirements associated with these rights.

- Users may download and print one copy of any publication from the public portal for the purpose of private study or research.

- You may not further distribute the material or use it for any profit-making activity or commercial gain

- You may freely distribute the URL identifying the publication in the public portal.

If the publication is distributed under the terms of Article 25fa of the Dutch Copyright Act, indicated by the "Taverne" license above, please follow below link for the End User Agreement:

www.tue.nl/taverne

Take down policy

If you believe that this document breaches copyright please contact us at:

openaccess@tue.nl

providing details and we will investigate your claim. 


\title{
A high-speed valve for surge control in a centrifugal compression system
}

\author{
Jan van Helvoirt, ${ }^{*}$ Bram de Jager, Maarten Steinbuch, and Nick Rosielle
}

\begin{abstract}
This paper deals with the critical problem of actuator limitations for the successful implementation of active surge control. We specify the capacity, bandwidth and allowable time delay for a control valve that can be used to actively suppress surge in a specific full-scale centrifugal compression system. The actuator requirements are obtained from closedloop simulations with a nonlinear simulation model of the compressor test rig. In order to meet the requirements, a new high-speed valve actuator had to be developed. We present the resulting actuator design and provide test results to illustrate that the control valve meets our design specifications.
\end{abstract}

\section{INTRODUCTION}

Surge is an unstable operating mode of turbocompressors that occurs at low mass flows. The instability is characterized by large limit-cycle oscillations in compressor flow and pressure rise. Surge reduces compressor performance and it can endanger the safe operation of the system.

The idea to actively suppress surge originated from [1]. In general, the goal is to stabilize the system to the left of the surge line by modifying its dynamic through the use of appropriate feedback. Many promising results of this approach have been reported in literature, see for example the surveys in [2-5].

An aspect of practical importance for surge control is the selection of the actuator(s). Systematic studies of sensor and actuator selection for surge control can be found in [6], [7]. Roughly, the following means of actuation can be distinguished within the literature: control valves, air injectors, and variable geometries like movable plenum walls and inlet guide vanes. A more recent idea is to use the electric drive of a compressor as an actuator, see for example [8]. Other actuators like loudspeakers, heaters and fuel regulators (for turbine-powered compressors) appear to be less suitable for large systems and therefore we will not discuss them here.

Surge control tests with a movable wall actuator are discussed in [9], [10]. Variable inlet guide vanes are mainly used in industry to optimize the performance and efficiency of turbocompressors during stable operation. The main drawback of variable geometries for active surge control in fullscale installations is that these actuators are complex, bulky and expensive.

Air injectors have proved to be highly effective actuators for surge suppression as well as for stabilization of rotating stall [11], [12]. Their drawback is the drastic modifications of the compressor internals that are required for installation, in particular for multi-stage machines. Furthermore, practical

The authors are with the Control Systems Technology Group, Dept. of Mechanical Engineering, Technische Universiteit Eindhoven, P.O. Box 513, 5600 MB Eindhoven, The Netherlands. j.v.helvoirtetue.nl experience with air injectors is limited and their reliability in industrial applications is still to be proven.

A close-coupled valve (located directly behind the compressor) yields the best surge control performance according to [6], [7]. Successful surge control experiments with control valve actuation, both with close-coupled and plenum bleed valves, are reported in [13-16]. Control valves are standard equipment in industry (e.g. in conventional surge avoidance systems) and installation of an active surge control valve is relatively easy.

Despite the progress in the field and the potential impact on industrial compressor operability, full-scale applications of active surge control have not been realized yet. A critical technological barrier is put up by the limited actuation capabilities as stated in for example [5], [17].

In this paper we address this problem and focus on the actuator specifications that are required for active control of surge in a full-scale centrifugal compression system. We start with a brief introduction of the centrifugal compressor test rig and the available dynamic model for this system. We then discuss the actuator specifications and how they were obtained from closed-loop simulations. Finally, we present the design of a custom-made valve actuator and we provide test results to show that the high-speed control valve meets our design specifications.

\section{Centrifugal COMPressor Surge}

The results presented in this paper are based on experimental work with an industrial centrifugal compression system. In this section we introduce the test installation under study and we briefly discuss the nonlinear model of the compression system dynamics. After presenting some validation data we address the design of a linear quadratic regulator and Kalman state estimator (LQG control) that will be used during closed-loop simulations.

\section{A. Experimental setup}

The experimental setup is an industrial test rig, consisting of a single-stage centrifugal compressor, intake and discharge piping system and a throttle valve. Close to the compressor two additional valves are installed; a fast control valve and a slow throttle valve for precise adjustments of the compressor operating point.

The compressor is driven by an $1 \mathrm{MW}$ electric motor and operating speeds lie between 14,000 an 21,000 rev/min. Mass flows range from 1.8 to $3.7 \mathrm{~kg} / \mathrm{s}$ and pressure rises from 0.1 to 0.9 bar. The system is equipped with an orifice flow meter, temperature, static pressure and stagnation pressure probes. All compressor measurements presented here were 
TuB02.1

TABLE I

PARAMETERS OF THE COMPRESSION SYSTEM

\begin{tabular}{|l|l|l|}
\hline Parameter & Value & Unit \\
\hline \hline compressor duct length $L_{c}$ & 10.6 & $\mathrm{~m}$ \\
compressor duct area $A_{c}$ & 0.0255 & $\mathrm{~m}^{2}$ \\
suction volume $V_{1}$ & 3.57 & $\mathrm{~m}^{3}$ \\
suction piping length $L_{1}$ & 29.6 & $\mathrm{~m}$ \\
discharge volume $V_{2}$ & 9.82 & $\mathrm{~m}^{3}$ \\
discharge piping length $L_{2}$ & 41.9 & $\mathrm{~m}$ \\
\hline
\end{tabular}

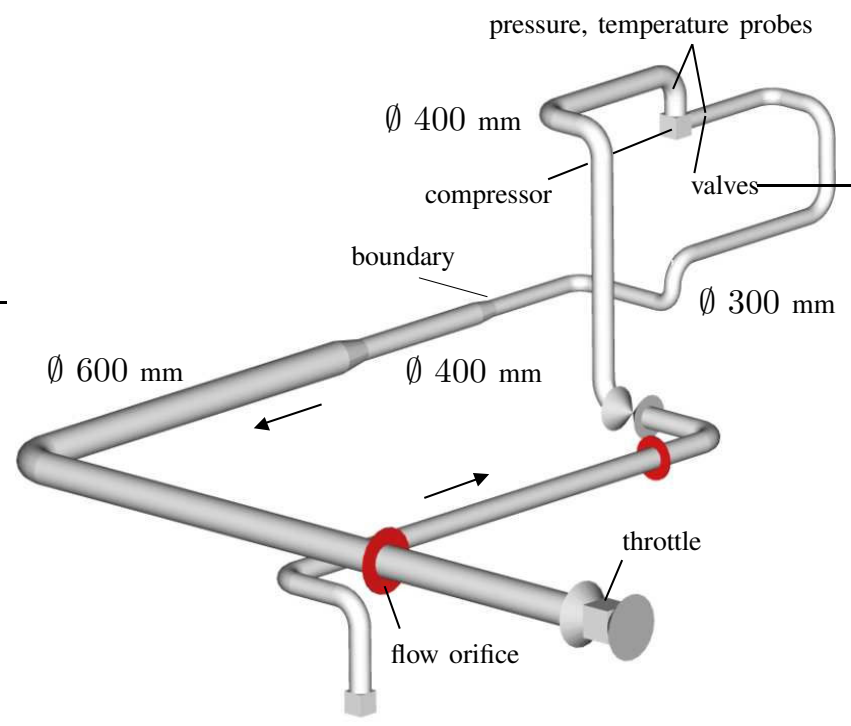

Fig. 1. Piping layout of the compression system.

taken with a dedicated data-acquisition system at a sample rate of $256 \mathrm{~Hz}$. The main characteristics of the setup are summarized in Table I and more details can be found in [18].

A layout of the piping system is shown in Fig. 1. We point out that the discharge piping of the investigated system is exceptionally long in comparison with other test facilities discussed in literature. The combination of piping dimensions and typical speeds, flows and pressure rises of the installation make it a good representation for a single stage of compression systems in the (petro)chemical industry.

\section{B. Dynamic model}

The dynamic behavior of turbocompressors during surge can often be described by lumped parameter models, similar to the well-known Greitzer model. However, in the long piping system of the studied test rig, acoustic waves with significant amplitude occur during surge. Since wave phenomena are not captured well in lumped parameter models, a more involved dynamic model was developed for the investigated compression system. Details on the development and validation of this model are given in [18].

The two-port structure of the dynamic model, including piping acoustics, is depicted in Fig. 2. The model consists of an impulse balance for the compressor, including a nonlinear compressor characteristic (see Fig. 4), a mass balance for

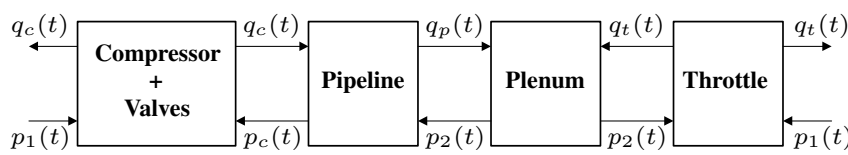

Fig. 2. Two-port model with flows $q(t)(=\dot{m} / \rho)$ and pressures $p(t)$.

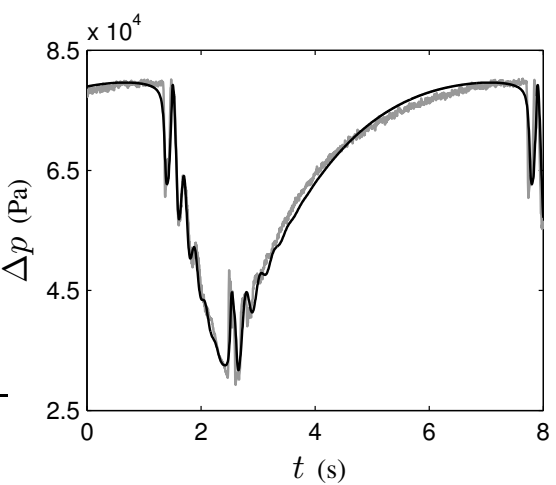

Fig. 3. Pressure measurement (gray) and simulation (black) during surge

the plenum volume, static valve characteristics (see Fig. 4), and a transmission line model that describes the acoustics of the discharge piping. Fig. 3 shows both the measured and simulated pressure difference during a single surge cycle.

\section{Control design}

Our goal is to obtain actuator specifications through closed-loop simulations. For this purpose any controller that stabilizes the system under realistic (simulated) conditions is adequate. The design of a stabilizing LQG controller is straightforward and provides some means of tuning the closed-loop such that control energy is minimized, and thereby realizing a large domain of attraction [16, pp. 47].

Therefore, we will design an LQG controller for the linearization of the compressor model around a specific unstable operating point. Fig. 4 illustrates how an operating point can be selected by opening or closing the throttle valve(s). We point out that the only measurable state of the resulting linear state-space model $(A, B, C, D)$ is the compressor discharge pressure $p_{c}(t)$. Accurate dynamic mass flow measurements are not available and there exist no straightforward relations between the six internal states of the transmission line model and measurable variables.

The reference for the controller is the value of the discharge pressure that corresponds to the selected operating point. The operating point is specified as a percentage of the mass flow $\left(\dot{m}_{c}(t)\right)$ at the surge line.

We use a standard LQ regulator to obtain a state-feedback law $u=-K x$ that minimizes the quadratic cost function

$$
J(u)=\int_{0}^{\infty}\left(x^{T} Q x+u^{T} R u\right) d t
$$

with $x, u$, and $y=x$ the state, input and output vectors, respectively and weights $R$ and $Q$ as design parameters. The state vector consists of the mass flow $\dot{m}_{c}$, discharge pressure $p_{c}$, and the six internal states of the transmission line model 


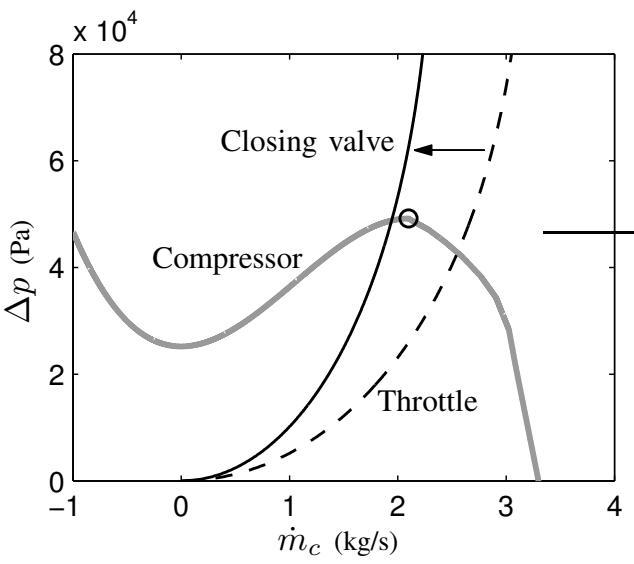

Fig. 4. Compressor and throttle characteristics; $o=$ surge point

for the piping acoustics. The control input $u$ represents the control valve opening that can vary between 0 (closed) and 1 (fully open).

In order to have access to the unmeasurable states, a Kalman filter

$$
\dot{\hat{x}}=A \hat{x}+B u+L(y-C \hat{x}-D u)
$$

with filter gain $L$ is designed. This filter provides an estimate $\hat{x}(t)$ such that $u=-K \hat{x}$ remains optimal. The covariances $\mathbb{E}\left(w w^{T}\right)=W, \mathbb{E}\left(v v^{T}\right)=V$ of the process noise $w$ and measurement noise $v$, respectively, are considered to be design parameters.

The controller that was used to obtain all results in the remainder of this paper, was designed for an operating point at $95 \%$ of the surge mass flow with a nominal control valve opening of 0.5 . The weight $Q$ was set to $I$ and we used $R$ to tune the controller. We remark that the right-half plane zero present in the linearized system model imposes a lower bound on the achievable bandwidth. Hence, further reduction of $R$ after reaching this bandwidth is not useful. Fortunately, minimizing control effort requires a large $R$. Similar arguments hold for choosing $W=I$ and $V$ low to achieve the best possible loop transfer recovery. However, noise in the system (variance $2 \cdot 10^{4}$ in experiments) requires a minimal value of $V$ to avoid actuator saturation.

Numerical tuning gave $R=5 e 7$ and $V=5 e 7$ as suitable values. The large numerical values are caused by the fact that the mass flow is expressed in $\mathrm{kg} / \mathrm{s}(\mathcal{O}(1))$ while pressures are in $\mathrm{Pa}\left(\mathcal{O}\left(10^{5}\right)\right)$. The result of a closed-loop simulation in Fig. 5 shows that the controller stabilizes the system when the mass flow is throttled down towards the normally unstable operating point that is reached after $30 \mathrm{~s}$.

\section{Surge CONTROL VAlVE}

This section deals with the specifications of a control valve actuator that are required to stabilize the centrifugal compression system under study. First, we discuss the various specifications that are considered and how they are quantified through numerical simulations. Secondly, we will elaborate on the realization of an actuator prototype and
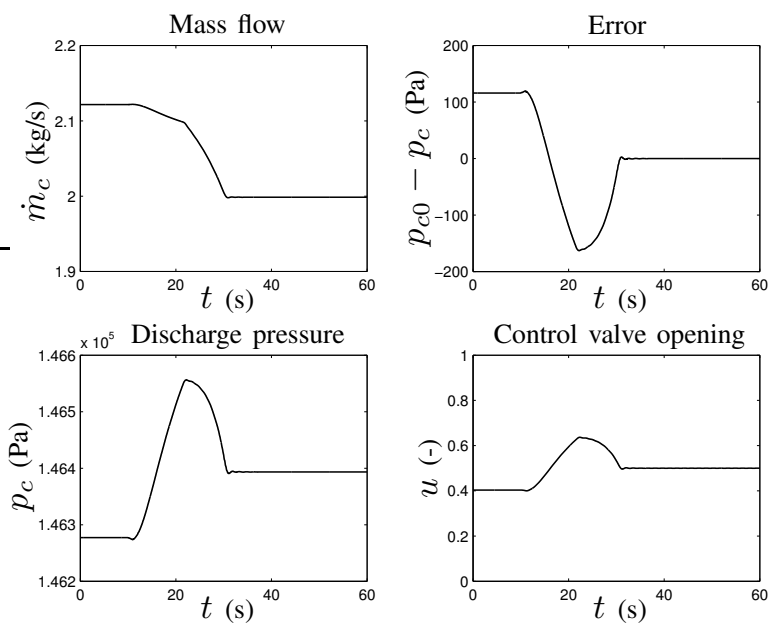

Fig. 5. Closed-loop simulation without valve dynamics, time delay and noise; nominal operating point $\left(\dot{m}_{c 0}, p_{c 0}, u_{0}\right)=\left(1.99,1.464 \cdot 10^{5}, 0.5\right)$.

present the resulting design. Finally, experimental results are presented to demonstrate that the actuator meets all the imposed requirements.

\section{A. Actuator requirements}

From literature (e.g. [5], [16] and our own investigations we know that the bandwidth and, even more important, the valve capacity are important specifications for a surge control valve. The control valve must respond fast enough to commands from the surge controller. Furthermore, changing the valve opening must have a significant influence on the pressure behind the compressor in order to provide adequate damping of surge oscillations. Another well-known issue is the negative effect of time delays between a control command and valve response on the closed-loop stability, see [17], [19].

Given the arguments above, we focussed on defining quantitative specifications for the valve capacity, bandwidth and the maximum allowable time delay. Other specifications as the life span, power requirements, efficiency and costs, although of practical importance, were not taken into consideration in this research.

We performed numerous closed-loop simulations in the presence of bandlimited white process noise (variance $2 \cdot 10^{4}$ ) while subsequently varying the valve capacity, bandwidth, and time delay. The valve dynamics are represented by a third order low-pass filter (see also [19]), representing a massspring-damper system with a bandwidth equal to the cut-off frequency of the filter. The valve capacity was varied by modifying the so-called $K_{v}$ value, see [20], of a standard control valve for which an accurate flow characteristic was available. We introduced a single time delay of variable length between controller output and valve position to represent all possible electronic and mechanical delays.

Some typical results from the simulations are shown in Fig. 6 in which the compressor goes from a stable to an unstable operating point (without control) between $t=20$ and $t=40 \mathrm{~s}$ by slowly closing one of the throttle valves. The 

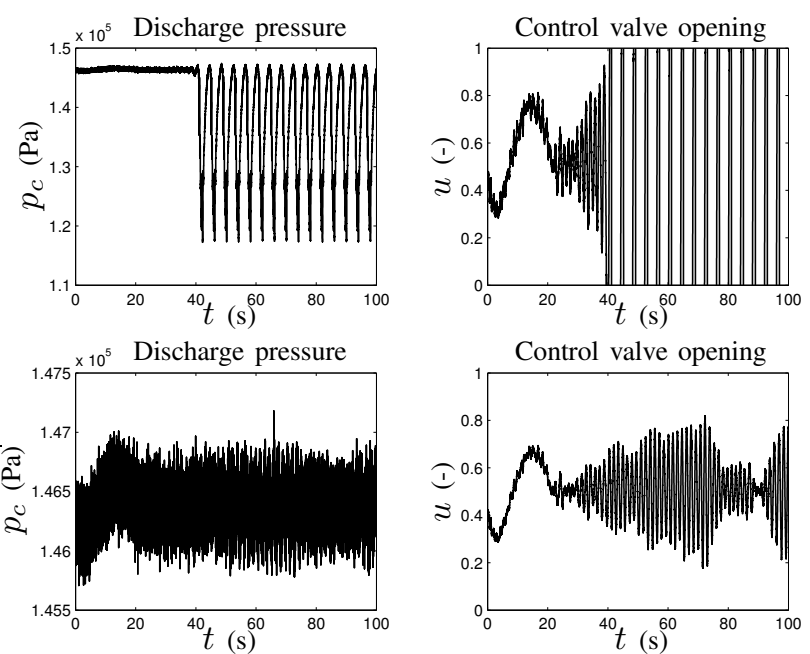

Fig. 6. Closed-loop simulation with $K_{v}=30$ (upper figures) and $K_{v}=$ 40 (lower figures); $t_{s}=0.0625 \mathrm{~s}$ and $\tau=0.01 \mathrm{~s}$, nominal operating point $\left(\dot{m}_{c 0}, p_{c 0}, u_{0}\right)=\left(1.99,1.464 \cdot 10^{5}, 0.5\right)$, variance process noise $2 \cdot 10^{4}$.

TABLE II

DESIGN SPECIFICATIONS FOR THE SURGE CONTROL VALVE

\begin{tabular}{|l|l|l|}
\hline Parameter & Value & Unit \\
\hline \hline control valve capacity $K_{v}$ & $\geq 40$ & $\mathrm{~m}^{3} / \mathrm{h}$ \\
control valve bandwidth $f_{c}$ & $\geq 16$ & $\mathrm{~Hz}$ \\
actuator time delay $\tau$ & $\leq 0.01$ & $\mathrm{~s}$ \\
\hline
\end{tabular}

results in Fig. 6 clearly show that the compression system is only stabilized when the capacity of the control valve is chosen large enough. The specifications for the control valve actuator that we obtained from the simulations are summarized in Table II.

Additional simulations showed that increasing $K_{v}$ well above the specified value relaxes the bandwidth and time delay requirements. However, a larger bandwidth or smaller time delay has hardly any effect on the minimum valve capacity that is needed to stabilize the system. Hence, we conclude that the valve capacity is the most critical requirement for the surge control actuator.

\section{B. Actuator design}

Given the design specifications obtained from the closedloop simulations, we first investigated if they could be met with a commercial control valve actuators. Since this appeared not to be the case, we proceeded with designing a custom-made control valve actuator. Details of the development will be omitted here and we will only address the most important design choices.

Firstly, a choice was made to use a commercially available valve with a known flow characteristic. We selected a 50 $\mathrm{mm}$ diameter sliding gate valve with a $K_{v}$ value of 45 $\mathrm{m}^{3} / \mathrm{h}$, based on previous experience with this type of valves. Furthermore, this valve has a linear relation between capacity and valve opening, a relatively low moving mass of 0.353 $\mathrm{kg}$, and a short stroke of $8 \mathrm{~mm}$.
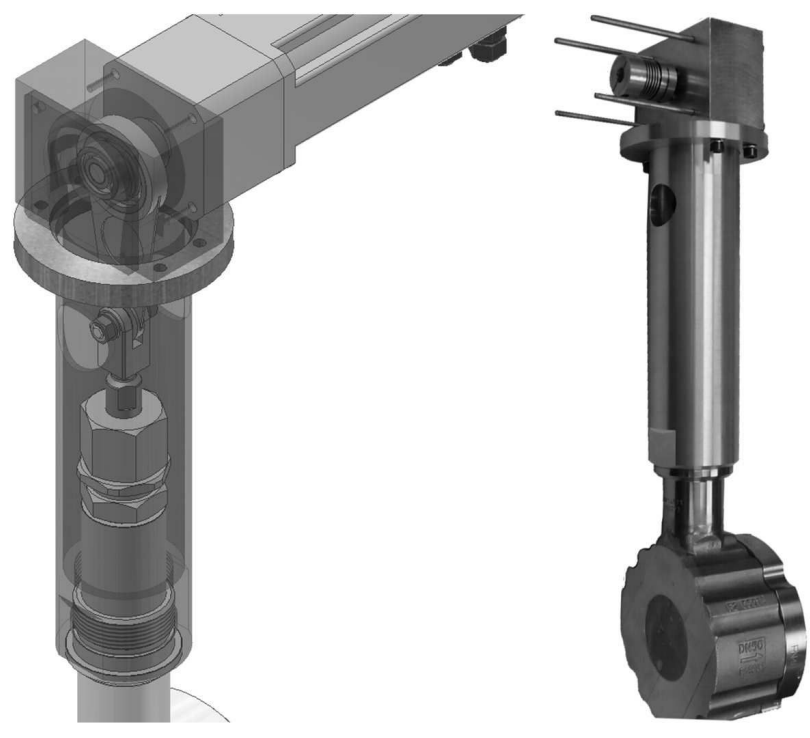

Fig. 7. Assembly drawing of design and photograph of final prototype.

Secondly, we chose to use an electric servo motor as actuator. In general an electric motor introduces less time delay in comparison with pneumatic actuators. Furthermore, designing an electro-mechanical system is less complicated and it requires less auxiliary equipment than hydraulic and pneumatic actuators. In order to achieve a direct and compact transmission of the motor rotation into a valve translation, an eccentric disc was mounted on the motor shaft and the disc was connected to the valve stem with a connecting rod.

Finally, for the selection of a suitable servo motor, straightforward dynamic calculations were performed where we took into account the required bandwidth, the various masses and inertias, the transmission ratio, conservative estimates of transmission efficiency and valve friction (estimated: 100 $\mathrm{N}$, measured on tensile test bench: $45 \mathrm{~N}$ ). Through a trialand-error selection procedure we found a motor that was able to meet the following demands: a peak torque of $2.32 \mathrm{Nm}$, peak acceleration of $26959 \mathrm{rad} / \mathrm{s}^{2}$, maximum speed of 1642 $\mathrm{rev} / \mathrm{min}$ and a power requirement of $300 \mathrm{~W}$.

The mechanism of the valve actuator and a photograph of the realized prototype are shown in Fig. 7. Operation of the valve is possible through the communication software of the power amplifier and motor control module, which are not shown here.

\section{Design evaluation}

After the construction and assembly of the actuator prototype, various tests where conducted to evaluate if the design specifications were met. After installation and initialization of the valve and motor electronics, we first tested the response of the valve with a sequence of step commands of arbitrary size. The results are shown in Fig. 8 and from this and similar experiments we concluded that the time delay specification was met. In the entire chain "controller board, motor electronics, actuator, encoder, controller board" only one sample time delay, i.e. $\tau=0.001 \mathrm{~s}$, was found. However, 

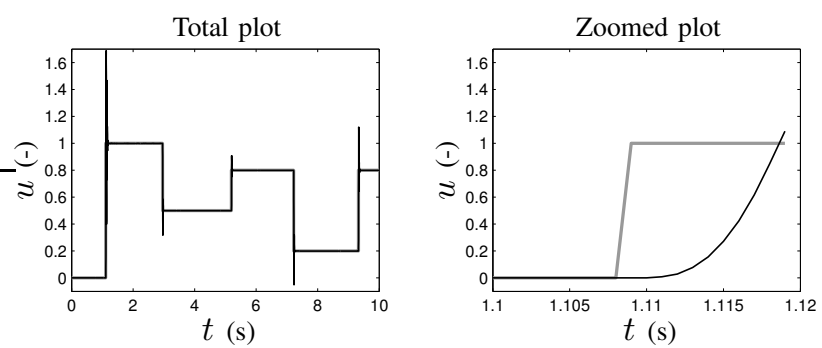

Fig. 8. Step reference (gray) and control valve response (black).

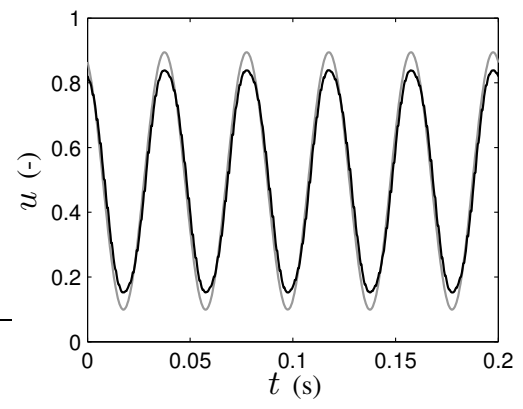

Fig. 9. Sine reference (gray) at $25 \mathrm{~Hz}$ and control valve response (black).

we point out that the valve response has significant overshoot at large amplitude steps, indicating the need for fine-tuning of the motor position controller.

Secondly, we made an attempt to measure a transfer function of the actuator dynamics. However, due to the significant amount of friction in the moving parts of the valve (due to rubber seals), a linear transfer function could not be measured. A possible method to tackle this problem is to apply friction compensation. However, we followed a more straightforward approach by applying a sinusoidal position command with an amplitude corresponding to $80 \%$ full stroke and a varying frequency. The result for a $25 \mathrm{~Hz}$ sinusoid is shown in Fig. 9. This measurement indicates that the bandwidth of the system is located around $22 \mathrm{~Hz}$ and this result was confirmed by various other step and impulse response experiments.

We point out that a bandwidth of $22 \mathrm{~Hz}$ is almost double the speed of commercial control valves of similar size. For example, a standard sliding gate valve with a $K_{v}$ value of 6.4 and a conventional pneumatic actuator has a $12 \mathrm{~Hz}$ bandwidth and a time delay of $0.01 \mathrm{~s}$, see [17].

Thirdly, the control valve capacity was measured by the manufacturer of the sliding gate valve body in accordance with the ISO standard [20]. After reviewing the measurement data provided by the manufacturer, we found no need to conduct further experiments to verify the specified $K_{v}$ value $\left(45 \mathrm{~m}^{3} / \mathrm{h}\right)$, which is above the required value.

Finally, the control valve was installed in the test rig to conduct further tests at realistic operating conditions and to evaluate the designed surge controller. At the time of publication, successful suppression of surge with the designed control system has not been achieved yet. Discussing these experiments and the possible causes for failure is beyond the scope of this paper. Therefore, we cannot conclude whether or not the valve capacity is large enough to stabilize the studied compression system to the left of the surge line.

\section{DISCUSSION AND CONCLUSIONS}

In this paper we addressed actuator limitations as being one of the technological barriers for the successful application of surge control in full-scale compression systems. We used a new model for the surge dynamics and piping acoustics to design a stabilizing LQG controller for a specific centrifugal compressor test rig. The typical dimensions of the test rig and the detailed dynamic model allowed us to perform closed-loop simulations that are representative for industrial compressor applications.

We argued that there are three important requirements for surge control valves, namely the valve capacity, bandwidth and the introduced time delay. With the closed-loop simulation model we quantified the capacity, bandwidth and time delay specifications for a control valve actuator. These simulations showed that the valve capacity is the most critical requirement for successful surge control. The bandwidth and time delay requirements are somewhat related to each other since they both introduce a phase lag. This implies that an improvement in one of the two parameter relaxes the requirement imposed on the other.

Furthermore, we concluded that the design specifications for a control valve could not be met by a commercial actuator. Hence, we developed a custom-made control valve actuator that could meet the requirements. With some test results we illustrated the superior performance with respect to the achieved bandwidth and negligible time delay of this control valve compared to standard industrial control valves. In order to reduce the friction within the valve and thereby improve its dynamic behavior, we are currently working on an improved design of the valve body. Furthermore, the question whether or not the valve capacity is sufficient to actually stabilize the compression system remains to be answered.

Future work must focus on assessing the feasibility of active surge control for industrial compression systems. Such an assessment requires further improvements of simulation models and (nonlinear) control strategies, supported by experiments on the studied test rig and other systems. To facilitate experiments, work should continue on obtaining adequate actuator requirements for different industrial compression systems. Furthermore, a comparison of control valves with other types of actuators could provide more insight in the optimal actuator for full-scale surge control. Once a suitable actuator is available, practical requirements like reliability, life span, and costs must be taken into account to support acceptation of active surge control by industry once the technology proves to be successful.

\section{ACKNOWLEDGMENT}

The authors would like to thank J. de Vries for the design and realization of the mechanical components for the control valve prototype. 


\section{REFERENCES}

[1] A. H. Epstein, J. E. Ffowcs Williams, and E. M. Greitzer, "Active suppression of aerodynamic instabilities in turbomachines," J. Propulsion and Power, vol. 5, pp. 204-211, 1989.

[2] B. de Jager, "Rotating stall and surge control: A survey," in Proc. 34th IEEE Conf. on Decision and Control, New Orleans, LA, USA, 1995, pp. $1857-1862$.

[3] J. T. Gravdahl and O. Egeland, Compressor Surge and Rotating Stall: Modeling and Control. London: Springer, 1999.

[4] G. Gu, A. Sparks, and S. S. Banda, "An overview of rotating stall and surge control for axial flow compressors," IEEE J. Control Systems Technology, vol. 7, pp. 639-647, 1999.

[5] J. D. Paduano, E. M. Greitzer, and A. H. Epstein, "Compression system stability and active control," Ann. Rev. Fluid Mechanics, vol. 33, pp. 491-517, 2001.

[6] J. S. Simon, L. Valavani, A. H. Epstein, and E. M. Greitzer, "Evaluation of approaches to active compressor surge stabilization," ASME J. Turbomachinery, vol. 115, pp. 57-67, 1993.

[7] M. van de Wal, F. Willems, and B. de Jager, "Selection of actuators and sensors for active surge control," J. Propulsion and Power, vol. 18, pp. 84-92, 2002.

[8] J. T. Gravdahl, O. Egeland, and S. O. Vatland, "Drive torque actuation in active surge control of centrifugal compressors," Automatica, vol. 38, pp. 1881-1893, 2002.

[9] D. L. Gysling, J. Dugundji, E. M. Greitzer, and A. H. Epstein, "Dynamic control of centrifugal compressor surge using tailored structures," ASME J. Turbomachinery, vol. 113, pp. 710-722, 1991.

[10] G. L. Arnulfi, F. Blanchini, P. Giannattasio, D. Micheli, and P. Pinamonti, "Extensive study on the control of centrifugal compressor surge," Proc. IMechE, Part A: J. Power and Energy, vol. 220, pp. 289-304, 2006.

[11] E. B. Nelson, P. J. D., and A. H. Epstein, "Active stabilization of surge in an axi-centrifugal turboshaft engine," ASME J. Turbomachinery, vol. 122, pp. 485-493, 2000.
[12] Z. S. Spakovszky, "Backward traveling rotating stall waves in centrifugal compressors," ASME J. Turbomachinery, vol. 126, pp. 1-12, 2004.

[13] J. E. Pinsley, G. R. Guenette, A. H. Epstein, and E. M. Greitzer, "Active stabilization of centrifugal compressor surge," ASME J. Turbomachinery, vol. 113, pp. 723-732, 1991.

[14] O. O. Badmus, S. Chowdhury, K. M. Eveker, and C. N. Nett, "Controloriented high-frequency turbomachinery modeling: Single-stage compression system one-dimensional model," ASME J. Turbomachinery, vol. 117 , pp. 47-61, 1995.

[15] W. M. Jungowski, M. H. Weiss, and G. R. Price, "Pressure oscillations occurring in a centrifugal compressor system with and without passive and active surge control," ASME J. Turbomachinery, vol. 118, pp. 2940, 1996.

[16] F. P. T. Willems, "Modeling and bounded feedback stabilization of centrifugal compressor surge," Ph.D. dissertation, Technische Universiteit Eindhoven, Eindhoven, The Netherlands, 2000.

[17] J. van Helvoirt, B. de Jager, M. Steinbuch, and J. Smeulers, "Practical issues in model-based surge control for centrifugal compressors," in Proc. IMechE 9th European Fluid Machinery Congress, The Hague, The Netherlands, 2006, pp. 285-295.

[18] J. van Helvoirt and B. de Jager, "Dynamic model including piping acoustics of a centrifugal compression system," J. Sound and Vibration, 2007, accepted for publication.

[19] J. van Helvoirt, O. Bosgra, B. de Jager, and M. Steinbuch, "Approximate realization of valve dynamics with time delay," in Proc. 16th IFAC World Congress, Prague, Czech Republic, 2005.

[20] "IEC 60534-2-1 part 2-1: Flow capacity-Sizing equations for fluid flow under installed conditions," in Industrial-process control valves, 1st ed. Geneva: International Electrotechnical Commission, 1998. 